\title{
Inclusive marginalization? A critical analysis of the concept of disability, its framings and their implications in the United Nations Convention on the Rights of Persons with Disabilities
}

Jan Grue

\begin{abstract}
While eschewing an explicit definition, the United Nations Convention on the Rights of Persons with Disabilities (CRPD) understands "disability" primarily as the result of interactions between individually situated impairments and societally created barriers. This article draws on work in interdisciplinary disability studies to argue that the way "impairments" and "barriers" are framed in the Convention raise fundamental questions about a) the standard of comparison for the Convention's stated goal of full and equal societal participation for disabled people, and b) its recommended means of reasonable accommodation. The article further argues a) that CRPD framings may facilitate practices of inclusion and accommodation at the individual, rather than the structural level, b) that such practices risk inclusive marginalization, i.e. partial inclusion without genuine equality of opportunity, and c) that the normative goals of the CRPD require a more developed account of the structural and systemic causes of disability.
\end{abstract}

Key words: CRPD, disability, impairment, barriers, participation

\section{Introduction}

The UN Convention on the Rights of Persons with Disabilities ${ }^{1}$, hereafter the CRPD, represents the culmination of decades of work by activists, politicians, scholars, communities, and allies on recognizing the class of disabled persons as both a) fully deserving of human rights and $b$ ) underserved by existing protections. The CRPD, which currently has 160 signatories, with 175 ratifications and accessions, and 92 ratifications and accessions both of the Convention and its Optional Protocol, was adopted in 2006. This followed the UN Decade of the Disabled Persons (1983-1992) and the UN International Year of Disabled Persons (1981), which in turn was motivated by the growing international interest in disability rights and recognition during the $1970 \mathrm{~s}^{2}$.

There is little doubt that the CRPD is a progressive force in the advancement of disabled people ${ }^{3}$, who by most accounts constitute the world's largest and poorest minority, roughly one-seventh of humanity, most of whom live in the Global South ${ }^{4}$. The class of disabled people, most comprehensively understood, include anyone

\footnotetext{
${ }^{1}$ United Nations, Convention on the Rights of Persons with Disabilities and Optional Protocol (United Nations 2007).

${ }^{2}$ Diane Driedger, The Last Civil Rights Movement : Disabled Peoples' International (Hurst \& Co 1989).

${ }^{3}$ Paul Harpur, 'Embracing the New Disability Rights Paradigm: The Importance of the Convention on the Rights of Persons with Disabilities' (2012) 27 Disability \& Society 1; Vibeke Blaker Strand, 'Norway's Ratification of the UN Convention on the Rights of Persons with Disabilities: Highlighting Current Discourses in the Field of Human Rights in Norway' (2014) 32 Nordic Journal of Human Rights 75; Kjersti Skarstad and Michael Ashley Stein, 'Mainstreaming Disability in the United Nations Treaty Bodies' (2018) 17 Journal of Human Rights 1.

${ }^{4}$ WHO, 'World Health Organization: World Report on Disability' (2011).
} 
whose bodily structure or function is in some way permanently impaired (with the precise definition of impairment being a problem in itself; see below). Unsurprisingly, disabled people on average have lower education, income, and welfare levels than the general population. The particular purpose of the CRPD is to recognize and ameliorate this discrepancy.

Concurrent with the international emergence of disability rights discourse and the recognition of disabled people as a minority in need of particular protections - by the United Nations, states, NGOs, and other parties - there has emerged an academic field of disability studies ${ }^{5}$. This field is multidisciplinary and influenced by traditions of action research as well as longstanding links with activist communities. Its aims are both descriptive and normative. Work in disability studies deals with the living conditions and quality of life of disabled people, but also with the theoretically and methodologically fraught questions of how and to what purpose disability and/or impairment should be defined.

Such questions have informed the field from its inception. "Disability" is not an intuitive concept nor a naturally occurring category. There is no clear distinction between disability, understood as a bodily condition, and chronic illness ${ }^{6}$. While folk definitions of disability and illness may frame the former as temporary and the latter as permanent, developments in medicine, changes in diagnostic procedures, and the sheer unpredictability of many bodily conditions means that even technically rigorous distinctions may in practice be quite tenuous. Nor is it clear whether the causes of disability can be clearly separated, e.g. into individual and environment categories. One consequence of this ambiguity is that estimates of the disabled proportion of any population varies considerably, depending not only on the quality of measurement tools but also on definitions and their interpretation. Another consequence is that it is hard to establish benchmarks of inclusion, i.e. of the successful protection of the rights of disabled persons.

The CRPD, which recognizes the evolving nature of the concept of disability, may be viewed as acknowledging some of the same circumstances and constraints as the discipline of disability studies, which are also political concerns. There is no explicit and/or formal definition of disability in the CRPD, but rather non-exhaustive list classes of persons that shall be included under its protections. This state of affairs is the result of complex processes ${ }^{7}$, and may in some respects be regarded as a positive; any attempt to sharply draw the line between disabled and non-disabled populations are inherently risky.

The arguments to follow assume that there is, however, no way to avoid an implicit definition of disability in a document such as the CRPD. By dint of its aims and scope

\footnotetext{
5 Lennard J Davis, The Disability Studies Reader (Routledge 2013).

${ }^{6}$ Susan Wendell, 'Unhealthy Disabled: Treating Chronic Illnesses as Disabilities' in Lennard J Davis (ed), The Disabilit Studies Reader (4th ed.) (Routledge 2013).

${ }^{7}$ Andrea Broderick, The Long and Winding Road to Equality and Inclusion for Persons with Disabilities: The United Nations Convention on the Rights of Persons with Disabilities. Dissertation (Maastricht University 2015); Stefan Trömel, 'A Personal Perspective on the Drafting History of the United Nations Convention on the Rights of Persons with Disabilities' in G Quinn and L Waddingto (eds), European Yearbook of Disability Law, vol 1 (2009); Anna Bruce, Which Entitlements and for Whom? The Convention on the Rights of Persons with Disabilities and Its Ideological Antecedents. Dissertation (Lund University 2014).
} 
and by its definition of other key concepts, the Convention frames the concept of disability (and its attendant concepts) in a way that makes them amenable to and suitable for being operationalized in particular ways. Such definitions are, inevitably and particularly in international conventions, compromises between differing interests as well as the ideals of consistency and rigor. This does not place them beyond the bounds of critique; the particular focus of this article is the mismatch between the stated purposes of the CRPD and the implications of its framing and implicit definition of disability.

This article interrogates the concept of disability and its attendant concepts in the CRPD from the perspective of disability studies, and with the intent of providing a critique in the Kantian sense ${ }^{8}$, i.e. a critical analysis of the conditions of thinking for a particular concept of disability - and the implications of such a concept. Disability studies provides the grounds for doing so through its mappings of multiple discourses of disability, i.e. different ways of encoding the phenomenon of disability into language across time periods, social fields, and cultures ${ }^{9}$.

In this critical perspective, the intersection of disability and the discourse of human rights is a historical development which produces a particular understanding of what disability is and what should be done about it - and understanding that is increasingly influential and therefore deserves scholarly attention. Besides international developments, there has been over the course of the last few decades a strong increase in rights-based discourse on disability in many states and entities, with general rightsand anti-discrimination laws (often building on previous legislation with a narrower and/or more health-related scope) introduced in, among others, the United States ${ }^{10}$ (1990), Australia ${ }^{11}$ (2002), the United Kingdom ${ }^{12}$ (1995), the European Union $(2000)^{13}$, Sweden ${ }^{14}$ (2003), and Norway ${ }^{15}$ (2008). While it is unclear to what extent such laws influence outcome measures for disabled persons, they represent a considerable shift in the framing of what disability is and what should be done about it.

This article has three main parts. The first part explicates and considers the underlying problematics of defining the concept of disability, with reference mainly to theoretical work in disability studies. The second analyzes the framings and implicit definitions that structure the CRPD, and their position in relation to disability theory. The third part discusses the implications of the CRPD definitions for the pragmatic understanding and politics of disability, with a particular emphasis on the dangers of

\footnotetext{
${ }^{8}$ Immanuel Kant and Werner S Pluhar, Critique of Judgment (Hackett Pub Co 1987).

${ }^{9}$ Martin Reisigl and Ruth Wodak, 'The Discourse-Historical Approach (DHA)' in Ruth Wodak and Michael Meyer (eds), Methods of Critical Discourse Analysis (2nd editio, Sage 2009); Sharon L Snyder and David T Mitchell, Narrative Prosthesis : Disability and the Dependencies of Discourse (University of Michigan Press 2000); Shelley Tremain, Foucault and the Government of Disability (University of Michigan Press 2005).

${ }_{10}$ Americans with Disabilities Act of 1990.

11 Disability Discrimination Act 1992 [Australia].

12 Disability Discrimination Act 1995.

${ }^{13}$ Council Directive 2000/78/EC of 27 November 2000 establishing a general framework for equal treatment in employment and occupation 2000.

${ }^{14}$ Act (2003:307) prohibiting discrimination.

15 Diskriminerings- og tilgjengelighetsloven [Anti-discrimination and Accessibility Act] 2008.
} 
inclusive marginalization, understood as inclusive practices that are delimited in such ways that genuine equality of opportunity is highly unlikely to result.

As indicated, the purpose of the article is not primarily to critique the intentions or actualities of the CRPD, but to demonstrate how rights-based discourse, of which the CRPD is a particularly salient example, is quite capable of framing of disability so that inclusive marginalization is a likely result. Crucially, there are both limitations to and problems with rights-based discourse on disability that a) constrain and detract from the primary purpose of the CRPD and $b$ ) need to be acknowledged in its implementation. The wide range of obligations flowing from the CRPD can be directed at individuals and systems; avoiding inclusive marginalization particularly requires systemic change, which in turn requires a framing of disability that is underdeveloped in the Convention.

\section{Defining disability: Fundamental issues and implications}

There is no universally accepted definition of disability. Very likely, this is due to both intrinsic and extrinsic factors, many of which impacted the decision not to include an explicit definition in the CRPD. Intrinsically, the phenomenon that is commonly denoted by the word disability has many aspects to it; insofar, every attempt at a conceptualization, definition, or internally consistent model of disability has resulted in an unsatisfactory elision of some aspects. Simply put, no one has managed to define disability in such a way that the sheer complexity of the phenomenon appears to have been described. Extrinsically, many institutions, groups, and individuals have differing or conflicting interests as to how disability should be defined, and thus incentives to prefer some aspects of the phenomenon to be highlighted or downplayed. Consequently, as I have argued elsewhere ${ }^{16}$, the concept of disability is in practice defined by multiple interdependent discourses, i.e. forms of language used in particular social spheres or fields, by different social actors, its meaning produced as much by practices of usage as by technical definitions. In this situation, implicit definitions, emerging from framing and context, may have considerable impact.

Historically, the logic of disability discourse has played out, both in the short term and in the longue durée, as a complex interaction between at least six different forms of discourse, all of which have ways to define disability: a) theological and moral discourses ${ }^{17}$, b) medical discourses ${ }^{18}$, c) political-economic discourses ${ }^{19}$, d) legal discourses $^{20}$, e) psycho-social-interactional discourses ${ }^{21}$, and f) cultural discourses ${ }^{22}$.

\footnotetext{
16 Jan Grue, Disability and Discourse Analysis (Routledge 2015).

${ }^{17}$ Henri-Jacques Stiker, A History of Disability (University of Michigan Press 1999).

18 Irving Kenneth Zola, 'Healthism and Disabling Medicalization' in Ivan Illich (ed), Disabling professions (Marion Boyars 1977); Irving Zola, 'Medicine as an Institution of Social Control' (1972) 20 The Sociological review 487.

${ }_{19}$ Deborah A Stone, The Disabled State (Temple University Press 1984); Michael Oliver and Colin Barnes, The New Politics of Disablement (Palgrave Macmillan 2012).

${ }^{20}$ Harlan Hahn, 'Antidiscrimination Laws and Social Research on Disability: The Minority Group Perspective' (1996) 14 Behavioral Sciences \& the Law 41.

${ }^{21}$ Carol Thomas, Female Forms : Experiencing and Understanding Disability (Open University Press 1999).

22 Sharon L Snyder and David T Mitchell, Cultural Locations of Disability (University of Chicago Press 2006).
} 
This list could of course be infinitely disputed and reorganized; the aim here is not to settle discussion on the matter, but to argue a) that there are different and relatively coherent ways to view disability that in turn imply ways to formally mode ${ }^{23}$ it, b) that such models are central to the production of socio-politically influential discourse, and c) that such discourses take on lives of their own, generating unintended consequences. There have of course been attempts to create a holistic understanding of disability, including political and economic factors, psycho-emotional and socialinteractional factors, and cultural factors, e.g. by defining disability a complex predicament ${ }^{24}$. However, the historical evidence shows that all definitional attempts, whether explicit or implicit, will inevitably force some priorities ahead of others.

The canonical example of this dynamic is the conflict between medical and social models of disability, which was particularly salient in the 1970s and 1980s but is still ongoing. The conflict between medical and social models remains a touchstone in disability studies literature, perhaps because it is relatively easily understood and clearly drawn.

The "medical model" is conventionally linked to the World Health Organization's International Classification of Impairments, Disabilities, and Handicaps ${ }^{25}$, which suggested that disability should be defined as functional limitation and understood as being caused by individual pathology. It was seen by activists and academics ${ }^{26}$ as a calcified and institutionalized way of thinking of disability as a problem locatable in individual bodies, which implied medical (or even surgical) solutions to problems that were in fact social (as well as economic, political, and legal). By contrast, a radical social model developed by UK activists ${ }^{27}$ proposed that disability should be defined as social, economic, and political oppression and understood as being caused by the marginalization of people with impairments.

The implications of each model should be clear. The medical model implies that attention should be paid largely to individual pathologies, while the social model implies that marginalization processes should be targeted. Consequently, each model ignores a significant range of factors that are at the very least relevant both to understanding and ameliorating disability. Most subsequent efforts to define and model disability have attempted to bridge this gap in some way, and to come up with a definition that will account for all relevant factors that explain disability, so that each factor can be targeted and disability - understood as particular predicament ameliorated to the greatest extent possible. Nevertheless, the intrinsic complexity of the phenomenon of disability insures that universality or neutrality of definition is all but impossible.

\footnotetext{
${ }^{23}$ Carol Thomas, 'How Is Disability Understood? An Examination of Sociological Approaches' (2004) 19 Disability \& Society 569.

24 Tom Shakespeare, Disability Rights and Wrongs (Routledge 2006).

25 WHO, International Classification of Impairments, Disabilities, and Handicaps (World Health Organization 1980).

${ }^{26}$ UPIAS, 'The Fundamental Principles of Disability'; Vic Finkelstein, 'To Deny or Not to Deny Disability - What Is Disability?' (1988) 74 Physiotherapy 650; Michael Oliver, The Politics of Disablement (MacMillan Press 1990).

27 UPIAS (n 26).
} 
Since the 1990s, multifactorial models of disability have generally prevailed, though arguably only in certain discourse ${ }^{28}$. They certainly dominate academic discourse, that of the humanities and social sciences in particular, and much of political discourse, concerned with anti-discrimination and rights. However, much of medicine, by dint of disciplinary structures and constraints, still treats disability as a property of individuals, a problem to be solved by particularist intervention.

The point here is not that disability can be consistently defined as either a property of individuals or a structural consequence of social organization, but the struggle over definitions was and remains a proxy for the struggles about policy. Thus, if legislation is passed wherein disability is defined as a complex phenomenon involving individuals and societal structures, this may suggest that a socio-political definition is winning out over a medicalizing, individualist definition. But if said legislation mainly enables individual/particularist policy, then for practical purposes the opposite is the case. And indeed, as I have pointed out elsewhere, there are examples of this dynamic $^{29}$, where the implicit definitions of disability end up subverting the explicit definitions (or lack of such).

\section{Framing disability in the CRPD}

As with other documents whose remit depends upon some kind of delimitation of disability, so also with the UN CRPD. It does not include an explicit definition, but it does draw on certain discourses, it models disability in a particular way, and implies a range of normative implications. For these reasons it de facto defines disability in a particular way; this is inevitable but it is also of analytical interest. The closest that the CRPD comes to a central definition of disability is Article 1, which states the Convention's main purpose:

The purpose of the present Convention is to promote, protect and ensure the full and equal enjoyment of all human rights and fundamental freedoms by all persons with disabilities, and to promote respect for their inherent dignity. Persons with disabilities include those who have long-term physical, mental, intellectual or sensory impairments which in interaction with various barriers may hinder their full and effective participation in society on an equal basis with others.

The implicit definition of disability given here is, firstly, based on the relationship between impairments and disabilities. "Impairments" is not defined in the Convention or Optional Protocol, but is commonly understood (e.g. in the World Health Organization's International Classification of Functioning, Disability, and $\mathrm{Health}^{30}$ ) as a problem with "physical, mental, intellectual or sensory" function or structure; it is this understanding that informs the CRPD definition.

\subsection{Defining “impairment”}

\footnotetext{
${ }^{28}$ Grue (n 16).

${ }^{29}$ Jan Grue, 'Is There Something Wrong with Society, or Is It Just Me? Social and Medical Knowledge in a Norwegian Anti-Discrimination Law' (2010) 12 Scandinavian Journal of Disability Research 165.

${ }^{30}$ WHO, Icidh-2: International Classification of Functioning and Disability (WHO 1999).
} 
In this view, impairments are discrete and consistently identifiable features of individuals. This position has considerable intuitive appeal. There is, however, a considerable body of disability studies literature which disputes it, arguing that impairments, too, are not biophysical givens, but are to some extent socially constructed along two dimensions. In this contrasting view, impairments are neither consistently identifiable as such nor wholly locatable in individual bodies. Rather, they represent points along the continuum of human capabilities, which must in turn be understood in the context of (variable) natural and built environments.

The argument about discreteness is grounded in a critical analysis of the history of normality and statistics ${ }^{31}$, which points out that many "problems" of body structure or functioning can be more neutrally described as significant deviation from the mean. While human capabilities can be described dichotomously - seeing/not seeing, walking/not walking - the continuum is a more accurate representation. Terms such as "legal blindness" or even "blindness" do not imply a complete lack of visual ability. The cut-off point for when a certain level of ability becomes definable as an impairment is neither wholly arbitrary nor wholly deterministic; it is a matter of complex negotiations, explored (aside from in disability studies) in the sociology of $\operatorname{diagnosis}^{32}$.

The argument about context, linked to that about discreteness, stresses the contextual nature of the "problem" frame. It has been particularly developed by scholars of Deaf Studies and the Deaf community ${ }^{33}$. The "problem" of not hearing is here seen as inextricably linked to the presence or absence of the opportunity to communicate using sign language, which, historically, has to a great extent been determined by sociopolitical conditions. Comparably, scholars in disability studies and activists of the neurodiversity movement has argued ${ }^{34}$ that, while representing real and substantial differences between individuals' capacities, conditions currently gathered under the

\footnotetext{
31 Georges Canguilhem, The Normal and the Pathological (Zone Books 1991); Lennard J Davis, 'Constructing Normalcy. The Bell Curve, the Novel, and the Invention of the Disabled Body in the Nineteenth Century' in LJ Davis (ed), The disability studies reader (Routledge 1997); Lars Grue and Arvid Heiberg, 'Notes on the History of Normality - Reflections on the Work of Quetelet and Galton' (2006) 8 Scandinavian Journal of Disability Research 232; Ingunn Moser, 'Against Normalisation: Subverting Norms of Ability and Disability’ (2000) 9 Science as Culture 198. 32 Annemarie Jutel, Putting a Name to It: Diagnosis in Contemporary Society (JHU Press 2011); Annemarie Jutel, 'Beyond the Sociology of Diagnosis' (2015) 9 Sociology Compass 841; Peter Conrad, The Medicalization of Society: On the Transformation of Human Conditions into Treatable Disorders (JHU Press 2008); Phil Brown, 'Naming and Framing: The Social Construction of Diagnosis and Illness' (1995) 35 J Health Soc Behav 34.

${ }^{33}$ Susan Burch and Hannah Joyner, Unspeakable : The Story of Junius Wilson (University of North Carolina Press 2007); JK Breivik, Deaf Identities in the Making: Local Lives, Transnational Connections (Gallaudet University Press 2005); B Woll and P Ladd, 'Deaf Communities' [2003] Oxford handbook of deaf studies, language, and.

${ }^{34}$ Dana Lee Baker, 'Neurodiversity, Neurological Disability and the Public Sector: Notes on the Autism Spectrum' (2006) 21 Disability \& Society 15 <https://www.tandfonline.com/doi/full/10.1080/09687590500373734> accessed 19 October 2018; Steven K Kapp and others, 'Deficit, Difference, or Both? Autism and Neurodiversity.' (2013) 49 Developmental Psychology 59 <http://doi.apa.org/getdoi.cfm?doi=10.1037/a0028353> accessed 19 October 2018; Pier Jaarsma and Stellan Welin, 'Autism as a Natural Human Variation: Reflections on the Claims of the Neurodiversity Movement' (2012) 20 Health Care Analysis 20 <http://link.springer.com/10.1007/s10728-011-0169-9> accessed 19 October 2018; Susanne Antonetta, A Mind Apart : Travels in a Neurodiverse World (Jeremy P Tarcher/Penguin 2005).
} 
umbrella label of autism spectrum disorder (ASD) can also be understood as an expression of the range of human sensory and cognitive variation, with strengths and weaknesses largely dependent upon socio-political arrangements.

Furthermore, contextual arguments have been developed with a basis in the philosophy and sociology of health and illness ${ }^{35}$. These arguments stress the dynamic and unpredictable nature of many forms of embodiment as well as the link between functioning and stages in the life course. They, too, contest the dichotomous division between people with and without impairments, and the conceptual integrity of the "problem" definition of impairments, which subsequently informs the "problem" definition of disability ${ }^{36}$. Societal expectations of the proper level of functioning varies for different social agents, e.g. children, pregnant women, the elderly, and inform our understanding of what exactly constitutes an impairment.

\subsection{Impairments and barriers}

The underlying problem of how to define "impairment" creates difficulties in delimiting the class of persons with disabilities. In the CRPD, persons with disabilities are effectively persons with impairments. Their impairments are ontologically prior to their interaction with "various barriers", and while it is this interaction that contextually produces their disablement, their status as a distinct class of persons is not dependent on context, since it is sufficient for the disablement to be hypothetically possible ("may hinder").

If, however, the definition of an impairment is to some extent dependent upon social arrangements, norms, and framings, then the conceptual distinction between (essentially biological) impairments and (essentially social) disabilities cannot be sustained. This also means that "barriers" must be viewed as a problematic term. In the CRPD definition, a barrier is what turns a person with an impairment into a disabled person. Hypothetically, a fully barrier-free society would contain persons with impairments, but no disabled persons. If, however, impairments are themselves (partly) constructed, it becomes difficult to distinguish barriers from other forms of social arrangements.

This has in fact proved to be the case. In a case widely reported as the exemplar of the restriction of disability rights ${ }^{37}$, the visual capability of "uncorrected visual acuity of 20/200 or worse ${ }^{38 "}$ was deemed by the United States Supreme Court not to constitute grounds for disability rights protection - since the means of visual correction where available - but also to constitute valid grounds for being barred from work as an

\footnotetext{
35 Susan Wendell, The Rejected Body : Feminist Philosophical Reflections on Disability (Routledge 1996); Wendell (n 6).

36 Tanya Titchkosky and Rod Michalko, 'The Body as The Problem of Individuality: A Phenomenological Disability Studies Approach' in Dan Goodley, Bill Hughes and Lennard J Davis (eds), Disability and Social Theory: New Directions and Developments (2012); Bill Hughes, 'Civilising Modernity and the Ontological Invalidation of Disabled People' [2012] Disability and Social Theory: New Developments and Directions 17; Bill Hughes, 'Being Disabled: Towards a Critical Social Ontology for Disability Studies' (2007) 22 Disability \& Society 673.

${ }^{37}$ Ruth Colker, The Disability Pendulum : The First Decade of the Americans with Disabilities Act (New York University Press 2005); Linda Hamilton Krieger, Backlash against the ADA : Reinterpreting Disability Rights (The University of Michigan Press 2003).

38 SUTTON V UNITED AIR LINES, INC (97-1943) 527 US 471 (1999) 130 F3d 893.
} 
airline pilot. The structural requirement of uncorrected vision above a certain level was here not deemed a "barrier" to "full and equal participation", highlighting the contingent status of both of these concepts in addition to that of impairment.

\subsection{Problems of circularity}

Is there a sensible way to define people with disabilities without reference to society in toto, and should such a definition be sought? Historically, attempts to establish clear and unambiguous definitions have tended to reduce society-related aspects of disability to medical problems, privileging medical power and resulting in medical reductionism. But the converse approach, which reframes the absence of disability as "temporary able-bodiedness" 39 and stresses the potential universality of disability, often fails to distinguish the people and groups most severely in need of protection.

The CRPD adopts a compromise position in its causal explanation of the exclusion of disabled people as the result of interaction between impairments and barriers. This begs the question of what exactly constitutes a barrier. As with "impairment", the term is not explicitly defined, but the six mentions times where it is mentioned produce an implicit understanding of "those features of society that exclude people with impairments". Although these two definitions are independently reasonable, taken together they constitute circularity: impairments are defined in terms of barriers while barriers are defined in terms of impairments.

This strategy has its advantages, e.g. an open-ended and potentially very inclusive scope for both the class of protected persons and the barriers targeted for elimination. It is a common gambit in anti-discrimination law, with the aforementioned 1990 Americans with Disabilities Act being perhaps the best-known example. Since any enumeration of impairments to be protected or barriers to be eliminated risks missing important present or future examples, it is deemed better not to do so. Fundamentally, this speaks to the multiform and complex nature of disability, which can never be unambiguously delineated from non-disability - since this line is by (non-medical) definition a product of particular historical and socio-political contexts.

However, a negative potential consequences of this strategy is that the identification of barriers becomes problematic in the extreme. Furthermore, a barrier might be understood with reference to the goal of "full and equal participation". Then, if an impairment is understood as any level of ability in any realm which, in interaction with any particular social arrangement, might result in a lack of full and equal participation, then barriers are ubiquitous, and probably encompass most of the built, social, and legal environment. This is such a broadly universalist interpretation of the key concepts that it is unlikely to be adopted in practice, but it leads to a more acute issue: what is the standard of comparison for "full and equal participation"?

\subsection{Privilege and stigma: Disability and standards of comparison}

By its nature, the CRPD is not and cannot be an exhaustive classification of barriers, impairments, and their possible interactions. However, its conceptual and theoretical

39 Thomas J Gerschick, 'Toward a Theory of Disability and Gender' (2000) 25 Signs: Journal of Women in Culture and Society 1263; Carol Appadurai Breckenridge and Candace A Vogler, 'The Critical Limits of Embodiment: Disability's Criticism' (2001) 13 Public Culture 349. 
problem of definitional circularity is significant because it leads to a more serious problem of implementation and standards of assessments. The CRPD has the explicit aim of securing "full and effective participation in society on an equal basis with others" for persons with disabilities, but it is unclear as to the meaning both of "full and equal" and "equal basis with others". Arguably, in conjunction with the standard of "reasonable accommodation", the CRPD's concept of disability provides grounds not for "full and equal" participation, but for what may be termed inclusive marginalization.

Originally used in reference to labor conditions and labor market access ${ }^{40}$, inclusive marginalization may be understood as a situation where a) rights are formally or legally guaranteed but not politically enforced, resulting in b) inclusion without genuine equality of opportunity. This situation is characteristic of disability in late modern societies, where public acknowledgement of disability is strongly linked to suspicions of malingering ${ }^{41}$, and attendant stigma ${ }^{42}$.

The underlying cause of this is linked to standards of comparison. Through the medical legitimation of impairments, disability provides, in most states, grounds for certain privileges, meant to ensure equality of opportunity. However, there is usually considerable political fear of creating too strong incentives to identify as disabled (relegating an unacceptably large segment of the population to the "needs-based" section of the economy ${ }^{43}$ ). Resources devoted to the disabled part of the population tend to receive considerable political scrutiny, and the commitment of such resources inevitable give rise to accusations of moral hazard. This means that disability often means second-class, poorly paid, unstable employment ${ }^{44}$, and that this comes to be seen as morally necessary. It shouldn't pay (literally and metaphorically) to be disabled; disabled people ought to be worse off than other people.

The question of standards of comparison for disabled people is enmeshed in politics and ethics, but also history. The concept and category we know as disability emerged as states attempted to manage socioeconomic and bodily exclusion, resulting in an enduring connection between a limited, medically legitimized capacity for particular kinds of work, and a marginalized yet partly protected sociopolitical status. There is, for example, an intimate link between disability, industrialization, and war. In English, according to Google's Ngram engine ${ }^{45}$, there are major spikes in usage of "disability" during the second industrialization following the American Civil War, after the calamities of the First World War and then the Second World War, aligned with the growth of the welfare state. It denoted the partial accommodation of war veterans and men who had been injured through industrial work. The "needs-based" section of the economy was established and expanded, partly motivated by fears of social unrest, and membership in this section remains a marker both of privilege and stigma. To be disabled, in developed societies, is to be a permanent client of the state,

\footnotetext{
${ }^{40}$ Susie S Porter, Working Women in Mexico City: Public Discourses and Material Conditions, 18791931 (University of Arizona Press 2003).

${ }^{41}$ Susan M Schweik, The Ugly Laws: Disability in Public (New York University Press 2009).

${ }^{42}$ Erving Goffman, Stigma: Notes on the Management of Spoiled Identity (Penguin 1963).

${ }^{43}$ Stone (n 19).

${ }^{44}$ Sarah F Rose, No Right to Be Idle: The Invention of Disability, 1840s-1930s (UNC Press Books 2017).

${ }^{45}$ Google Books, 'Ngram Viewer' (2013).
} 
with a diminished moral status; inclusive marginalization is the political expression of an implicit moral judgement.

Ultimately, inclusive marginalization is legitimized by the equation of bodily inferiority with moral inferiority. The heterogeneity and sheer size of the disabled portion of the population makes it inherently difficult to create standards of comparison. It is tempting, therefore, to assume a comparative standard of "simple abled-bodiedness" or absence of impairment. But this requires that the full range of variation in human capabilities be ignored. As disability scholars have pointed out, representations of an "average" or "normal" human being tend to have strong normative implications as well, as captured by the concept of the "normate", in the terminology of disability scholar Rosemarie Garland-Thomson ${ }^{46}$.

The problem of standards of comparison intersect with the definitional problem to create something of a paradoxical situation. If impairments are understood in a narrow sense, as easily identifiable and major "problems" in bodily structure or function, then disabled people are a highly disadvantaged group by comparison with the rest of humanity. If, by contrast, impairments are understood in a wide sense, as an expression of the range of human capabilities, depending on stages of the life course and social context, then it is exceedingly hard to draw the line between the disabled population and any other, comparable population. In both cases, the matter of how to achieve participation on an equal basis - by means of reasonable accommodation becomes highly problematic.

\section{Practical implementation: "Reasonable accommodation" and the social construction of normality}

Article 2 of the CRPD defines key concepts of the Convention, including reasonable accommodation, i.e. "necessary and appropriate modification and adjustments not imposing a disproportionate or undue burden". A number of observations can be made about this standard, first of all that it frames disability inclusion as a site of negotiation where the needs and preferences of those who govern existing systems and structures are pitted against the needs and preferences of disabled people and second that it is the standards of presently existing societies that provide the baseline for inclusion.

This point, also developed in legal contexts ${ }^{47}$, is essential to disability studies, which questions the legitimacy of "disability" as a legitimate signifier of essential difference. Such a view of disability It ignores the status of institutions and social systems as constructed - by humans, for (a certain type of) humans. The previously discussed arguments about the social construction of impairments have an obverse side, applying to systems and structures. For example: The built environment is an accommodation of the average human physique and capabilities. Stairs are not the only way to connect stories or floors in buildings; alternative choices are ladders and elevators. Ladders accommodate a relatively small proportion of humans, while

\footnotetext{
46 Rosemarie Garland-Thomson, Extraordinary Bodies: Figuring Physical Disability in American Culture and Literature (Columbia University Press 1997); Rosemarie Garland-Thomson, Staring : How We Look (Oxford University Press 2009).

${ }^{47}$ Shelagh Day and Gwen Brodsky, 'The Duty to Accommodate: Who Will Benefit' (1996) 75 Canadian Bar Review.
} 
elevators accommodate the vast majority. Stairs fall somewhere in the middle. Since stairs tend to represent the baseline for buildings, efforts are continuously made to accommodate a majority of human beings, and so to socially construct the "normal" human being.

Of course, the political reality of seeking accommodation aligns closely with the "modification and adjustment" suggested by Article 2. For example, physical access to buildings and services in the United States has, since the adoption of the Americans with Disabilities Act, been achieved partly through the use of litigation initiated by individuals - seeking piecemeal modification and adjustment. The consequences of this dynamic have been problematic ${ }^{48}$. With a basis in the moral logic that justifies inclusive marginalization, it is possible - and common - to accuse disability advocates of "overreach" when it comes to access and accommodation. Framing disability accommodation as adjustments to pre-existing structures supports the view that persons with disabilities are naturally pre-excluded from extant institutions and systems.

This logic applies across the social domains covered by the CRPD. As an example, the domain of education, described under Article 24, the achievement of "an inclusive education system at all levels" is linked to various States Parties' obligations, partly framed in negative, structural terms (avoiding non-exclusion), but mainly in positive, individual-centered obligations (providing access and individual support, and making reasonable accommodations for individuals). Persons with disabilities are framed as requiring particularist intervention in order to be accommodated, while the accommodation of the (statistically) average human being goes unmentioned.

\section{1 "Reasonable" and "undue": The challenge of disability heterogeneity and individual accommodation}

Outside strictly legal contexts, the "undue burden" part of the definition of reasonable accommodation aptly describes the moral response of many institutions and individuals. There is an established catalogue of arguments against disability accommodation; in terms of rhetoric and argument, they may be described as loci communes $^{49}$, i.e. commonplaces in the discourse of "undue burden". They serve as exemplifications of the logic of inclusive marginalization, made possible by the "naturally occurring problem" conception of impairments.

Tanya Titchkosky, in her book, The Question of Access ${ }^{50}$, gives a list of such commonplaces. The book is an in-depth discussion of accommodation and accessibility issues at the University of Toronto - a rich and ostensibly progressive institution in a rich and ostensibly progressive country. Since the CRPD is a document

\footnotetext{
48 Samuel R Bagenstos, 'The Perversity of Limited Civil Rights Remedies: The Case of Abusive ADA Litigation' (2006) 54 UCLA Law Review.

${ }^{49}$ Ruth Wodak, 'History in the Making/The Making of History' (2006) 5 Journal of Language and Politics 125; Tobias Reinhardt, "Topica / Marcus Tullius Cicero; Edited with a Translation, Introduction, and Commentary by Tobias Reinhardt'; Aristotle, Hugh Tredennick and ES Forster, Posterior Analytics / Aristotle ; [Translated] by Hugh Tredennick. Topica / Aristotle ; [Translated] by E.S. Forster (Harvard University Press ; Heinemann 1960).

50 Tanya Titchkosky, The Question of Access: Disability, Space, Meaning (University of Toronto Press 2011).
} 
with a global scope, as well as global potential reach and implications, with rich as well as poor countries as signatories, intended to affect the lives of disabled people in desperate straits as well as people whose lives are much better, it is worth remembering the context of Titchkosky's narrative.

The building on which Titchkosky centers her discussion is a relatively recent addition to the University of Toronto. It is catalogued as accessible to disabled people and has many signs and symbols that mark it as such. For example, many restrooms carry such signs. In practice, Titchkosky finds, much of the building is not really accessible. The terrain deviates from the map, making full and effective participation impossible.

Titchkosky then proceeds to catalogue the arguments provided by various university staff when she asks them the question of access - i.e. the question of what should be done about the lack of actual access. They largely amount to justifications for the status quo, for why no further resources should be expended on making the building accessible. The grounds provided include the amount of resources already spent, the low number of disabled people on campus, and the sufficiency of ad hoc arrangements (the availability of passing people for providing help to those who need it, etcetera). Titchkosky concludes:

The paradox [of disability in public] is this: the presence of disability almost always fades into an absence, and in many ways a dominant depiction of disability is that it should appear as if it is not present, not appearing ${ }^{51}$.

In her book, Titchkosky provides a stark view of the normative constraints upon "full and effective participation". The "presence" of disability in symbolic, noticeable form will serve as an indicator of success, whatever the actual, embodied, lived reality of disabled people - so long as the general public feels that a sufficient amount of resources has been expended. In practice, the achieved goal is inclusive marginalization.

\section{2 "Full and effective participation" vs inclusive marginalization}

The standard of "full and effective participation" recalls the World Health Organization's definition of health as the "complete state of physical, mental and social well-being, and not merely the absence of disease or infirmity 52 ." It establishes a normative ideal at odds with human variation and diversity. Furthermore, the framing of inclusive practices as special accommodations of individuals, rather than structural changes to align with a more accurate understanding of this variation and diversity, allows for the practices of accommodation described in the above section. Disability inclusion will in practice often tend toward minimal inclusion.

\footnotetext{
51 ibid 96.

52 World Health Organization, 'Preamble to the Constitution of the World Health Organization as Adopted by the International Health Conference, New York, 19-22 June, 1946; Signed on 22 July 1946 by the Representatives of 61 States (Official Records of the World Health Organization, No.'
} 
This is the practice exemplified by Titchkosky - in the context of accessibility, which is in principle more amenable to structural efforts - wherein disability is symbolically acknowledged, but each effort towards inclusion may rhetorically undermine subsequent efforts. Again, the moral logic of inclusive marginalization supports the case that it would be unreasonable to make things too accommodating.

This may be termed the Zeno's Paradox of disability inclusion: The closer one approaches the conditions of full and equal participation, the harder it becomes to sustain the arguments for finally achieving the goal. With reference to Stone and the interaction of disability privilege and disability stigma, flowing from the definitions of CRPD every instance of "special" (i.e. individual) accommodation is likely to generate stigma, unlike the pre-existing, and unmarked, instances of accommodations geared toward the majority of humanity. Once the utopian standard of full participation has been abandoned, "reasonable" accommodation may quickly deteriorate to whatever is deemed cost-effective. The point of comparison then becomes a minimum standard of participation, rather than "full and equal".

Titchkosky contends that inclusion may often take ineffective or ineffectual forms that nevertheless satisfy bureaucratic standards - her signal example being bathrooms that are marked with a wheelchair symbol but are nevertheless not wheelchair accessible because of their too-narrow doors. Her point speaks to the nature of equality. In many if not most cases, equal access means comparable access or equally good access. But compared to whom? If the provisions of the CRPD are interpreted according to a statistical mean - "full and equal participation" means "an average amount of participation" - that does not seem unreasonable. But the built-in structural deficits identified by Titchkosky (and others) imply that the end result is "somewhat less than average degree of participation".

This holds true as long as the "discrete problem" framing of impairments is preserved. Disability, then, implicitly remains a category of minimal inclusion or inclusive marginalization even by the lights of the CRPD. This entails the maintenance of disability as a special category requiring accommodation, but not to the extent of reorganizing systems and structures so that they do not become inherently exclusive.

\section{Is there an alternative to inclusive marginalization? A final note on disability utopias and disability theory}

True equality and the full participation of disabled people in society is utopian, but it is nevertheless the stated purpose not only of the CRPD. Utopian visions haunt disability studies, too. They are perhaps most vividly conjured by the South African activist Vic Finkelstein in a story to which he returned throughout his career ${ }^{53}$, about what the world might look like were the built environment adapted to the needs of people who use wheelchairs rather than people who walk. He envisions a village where every feature of the built environment is significantly different from its realworld equivalent; consequently, the very meaning of disability changes.

\footnotetext{
${ }^{53}$ Finkelstein (n 26); Vic Finkelstein, 'Reflections on the Social Model of Disability: The South African Connection.' [2005] Unpublished.
} 
To recapitulate, disability studies represents, in part, attempts to solve the "problem" of disability (and impairment) - but also to question the "problem" framework. Most modern theories of disability have, as does the CRPD, both descriptive and normative goals. The normative goals of equality are all but universal: to eliminate disability to the extent that it implies social marginalization. Major attempts to theorise and understand the phenomenon, including the so-called British Social Model ${ }^{54}$ with which Finkelstein's fable is associated, the North American minority model ${ }^{55}$, and the Nordic relational model ${ }^{56}$, all align to a considerable extent with the CRPD on this matter. It is their descriptive and analytical content that differ - and that difference has important implications.

The British social model, for example, explains disability as a function of the political and economic repression of people with bodies that deviate from a biomedical norm that is informed by existing power relations. It suggests that the remedy is wholly political: primarily, a comprehensive restructuring of the labor market and built environment. The minority model similarly explains disability as the political marginalization of people who exhibit embodied differences, analogous to embodied differences of skin color or sexual orientation, and prescribes a policy of diversity acknowledgement. From the perspective of both models of disability, the CRPD is alternately lacking in terms of true recognition of human diversity or in accounting for politically and economic repressive structures.

The human rights framework of the CRPD is closely connected to its understanding of relational disability as ontologically posterior to individual impairment. This connection is entirely logical on its own terms, being congruent with the identification of rights' violations on an individual as well as a group basis. However, since individuals' impairments are taken as given and ontologically prior to socially situated disability, the structural causes of disability are not fully accounted for. From this lacuna follow practical problems both of a descriptive and a normative nature. The CRPD's definitions of disability, impairments, and barriers, in turn shape its framing of reasonable accommodation and full and equal participation as acts of special or particularist inclusion that entail a particular burden upon society. Moreover, the CRPD's definition of disability obscures clarity regarding full and equal participation, allowing for "persons without impairments" to become a normative ideal.

This normative ideal is deserves criticism as well as critique. Should the category of "disability" ever really become superfluous or redundant, it will be because it has been supplanted by a comprehensive notion of diversity - as evident in human capabilities, and a corresponding set of societal arrangements, institutions and functions. This notion of diversity entails elaborations of what "full and effective participation" entails - elaborations that are not dependent on normative comparisons between the lives of people with and without specific impairment or chronic illness. This requires, too, an examination of the various arenas for participation - for

\footnotetext{
${ }^{54}$ Oliver and Barnes (n 19); Michael Oliver, 'Defining Impairment and Disability: Issues at Stake' in Colin Barnes and Geof Mercer (eds), Exploring the Divide (The Disability Press 1996).

55 Hahn (n 20).

56 Jan Tøssebro, 'Understanding Disability' (2004) 6 Scandinavian Journal of Disability Research

3; Dan Goodley, Disability Studies: An Interdisciplinary Introduction (SAGE 2010).
} 
example, work and employment. In her essay The Right not to Work: Power and Disability, Sunaura Taylor writes:

For many disabled people employment is unattainable. We often simply make inefficient workers, and inefficient is the antithesis of what a good worker should be. For this reason, we are discriminated against by employers. We require what may be pricey adaptations and priceless understanding. Western culture has a very limited idea of what being useful to society is. People can be useful in ways other than monetarily. The individuals who I marched with may not have paying jobs, but they spend hours each day organizing protests and freeing people from lives in institutions. Isn't this a valuable way to spend ones time? Disabled people have to find meaning in other aspects of their lives and this meaning is threatening to our culture's value system ${ }^{57}$.

Accommodation is often - politically and morally - conceived as a burden imposed by abnormal individuals upon society is a normative stance, and the equation of reasonable accommodation with cost-effective practices leads easily inclusive marginalization. The full and equal participation of every person with an impairment on par with the statistically average human being will never be cost-effective; such accommodation will remain profoundly unreasonable from an economic point of view.

Consequently, the CRPD's implicit definition of disability stands partly in contradiction to its normative goals. These contradictions need not undermine the convention's progressive function - its role in further the cause and advancing the rights of persons with disabilities - but they provide grounds for thinking more critically about what exactly it means by "persons with disabilities" and what it means to accommodate members of this category, as opposed to the equally constructed category "persons without disabilities". The next step is to acknowledge the way in which both categories are, to an extent, functions of the social, political, and economic environment, and how they provide the framework for how we understand individual rights - and the reasonable limit of their enforcement.

57 Sunaura Taylor, 'The Right Not to Work: Power and Disability' (2004) 55 Monthly Review. 